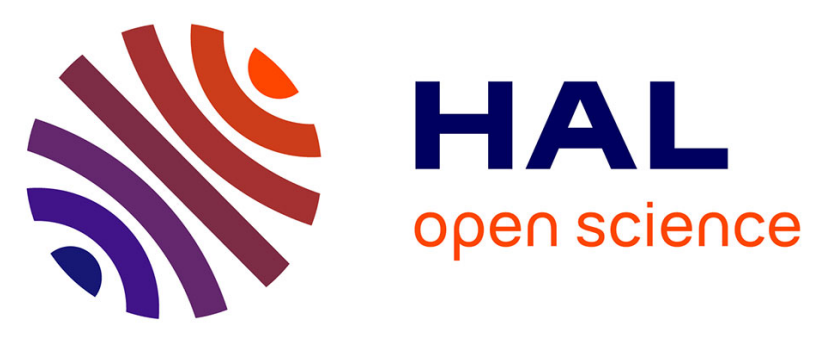

\title{
1H NMR Investigations of Activated Carbon Loaded with Volatile Organic Compounds: Quantification, Mechanisms, and Diffusivity Determination
}

Guirec Le Bozec, Sylvain Giraudet, Laurent Le Pollès, Pierre Le Cloirec

\section{- To cite this version:}

Guirec Le Bozec, Sylvain Giraudet, Laurent Le Pollès, Pierre Le Cloirec. 1H NMR Investigations of Activated Carbon Loaded with Volatile Organic Compounds: Quantification, Mechanisms, and Diffusivity Determination. Langmuir, 2017, 33 (7), pp.1605-1613. 10.1021/acs.langmuir.6b03608 . hal-01475698

HAL Id: hal-01475698

https://hal-univ-rennes1.archives-ouvertes.fr/hal-01475698

Submitted on 4 Jul 2017

HAL is a multi-disciplinary open access archive for the deposit and dissemination of scientific research documents, whether they are published or not. The documents may come from teaching and research institutions in France or abroad, or from public or private research centers.
L'archive ouverte pluridisciplinaire HAL, est destinée au dépôt et à la diffusion de documents scientifiques de niveau recherche, publiés ou non, émanant des établissements d'enseignement et de recherche français ou étrangers, des laboratoires publics ou privés. 


\title{
${ }^{1} \mathrm{H}$ NMR investigations of activated carbon loaded
}

\section{with volatile organic compounds: quantification,} mechanisms and diffusivity determination

\author{
Guirec Le Bozec*, Sylvain Giraudet, Laurent Le Polles and Pierre Le Cloirec
}

Ecole Nationale Supérieure de Chimie de Rennes, CNRS, UMR 6226, 11 allée de Beaulieu, CS 50837

35708 Rennes Cedex 07, France

* Contact Author: guirec.lebozec@ensc-rennes.fr

\begin{abstract}
Three volatile organic compounds (benzene, cyclohexane, dichloromethane) were adsorbed onto activated carbon fiber cloth. ${ }^{1} \mathrm{H}$ (MAS and PFG) NMR techniques were carried out and the signals were analyzed in terms of peak surface areas and shifts. These techniques were shown to be very useful for determining i) the intrinsic quantification of adsorbed molecules (VOC and/or water) in the porosity of the materials; the adsorption capacities ranged from 0.2 to $4 \mathrm{~mol} . \mathrm{kg}^{-1}$, ii) the mechanisms of interactions between adsorbed organic molecules and the carbon walls;
\end{abstract}


illustrations of positions of the molecule inside the pore volume are proposed; the proton-wall distance was less than $0.15 \mathrm{~nm}$, iii) the diffusivities; surface diffusion coefficients $\left(\mathrm{D}_{\mathrm{S}}\right)$ were estimated at $\approx 4.10^{-12} \mathrm{~m}^{2} \cdot \mathrm{s}^{-1}$ for cyclohexane, $\approx 1.10^{-11} \mathrm{~m}^{2} \cdot \mathrm{s}^{-1}$ for benzene and $\approx 4.10^{-11} \mathrm{~m}^{2} \cdot \mathrm{s}^{-1}$ for dichloromethane.

\section{KEYWORDS}

Solid NMR, Activated carbon, Volatile Organic Compound, Adsorption mechanisms, Diffusion coefficients

\section{INTRODUCTION}

In both industrialized and developing countries, volatile organic compound (VOC) emissions are among the causes of atmospheric pollution. They act as chemical precursors of pollutants like tropospheric ozone and can also directly impact human health. One of the main VOC treatment processes is adsorption onto active carbon (grains or fiber cloths). The high porosity of these materials enables high retention rates and a very wide range of gas flow rates (100 to 10,000 $\mathrm{m}^{3} / \mathrm{h}$ ) for a large diversity of organic molecules. In this context, knowledge of adsorbent supports and analyses of physical and chemical phenomena involved in the adsorption process are of utmost importance. These studies use several characterization methods and techniques. In general, porous volumes, specific surface areas, and pore size distributions can be deduced from the adsorption isotherm curves of nitrogen, as well as gases such as helium or $\mathrm{CO}_{2}{ }^{1}$. These isotherms are described by means of the BET model ${ }^{2}$ or, more recently, a model based on density functional theory ${ }^{3,4}$ calculations. From a chemical point of view, Boehm's method leads to the characterization and quantification of surface functional groups ${ }^{5}$. Calorimetric measurements 
(microcalorimetry $^{6,7,8,9}$, differential scanning calorimetry ${ }^{10,11,12}$ ) provide energetic values of adsorption interactions, in particular enthalpies and Gibbs energies. Isotherm, kinetic and breakthrough curves result from experimental data obtained through indirect measurements. Adsorbed quantities are deduced from the difference between non-adsorbed compound concentrations (remaining in the reactor atmosphere) and initial concentrations. Quantitative analyses of organics in the gas phase are performed by gas chromatography separation (the case of multicomponent adsorption) $)^{13}$. The detection and quantification of organics use spectroscopic or flame ionization detection (FID) methods ${ }^{14,15}$. From these experimental data, diffusion coefficient values are obtained by indirect means such as parametric correlations and adjustments in adsorption kinetic models ${ }^{16}$.

Earlier nuclear magnetic resonance (NMR) investigations of organic compounds adsorbed onto active carbons and non-carbon lattices were conducted in the late $1980 \mathrm{~s}^{17,18}$. Due to significant technical progress, NMR now appears as an additional analytical tool to enhance studies of adsorbed compounds onto host porous active carbons ${ }^{19}$. Most notably, NMR methods provide a dual benefit: non-destructivity and direct measurements of the adsorbed phase inside porous materials. Several studies have been carried out on non-carbon materials (MCM-41, zeolites, silicates). Pore size distributions have been characterized ${ }^{20}$. Furthermore, using pulsed field gradient (PFG) NMR methods, information concerning the diffusion and adsorbed phase behavior inside the porosity has been obtained onto mesoporous ${ }^{21,22}$ and nanoporous adsorbents ${ }^{23}$. NMR techniques applied to carbon materials revealed two specific features. First, a shift of a few ppm towards strong fields was observed for all NMR signals compared to the signal for pure organic compounds. Second, large peak broadness of the order of 10 ppm was noted. Complex signals are produced in the case of multicomponent adsorption or for carbons 
presenting a strong dependence of the chemical shift vs. adsorption sites. In such a case, line broadening and overlapping signals hide the spectrum deconvolution ${ }^{24}$. Nevertheless, fruitful studies using ${ }^{1} \mathrm{H},{ }^{13} \mathrm{C},{ }^{19} \mathrm{~F}$, and ${ }^{11} \mathrm{~B}$ NMR probes have been published ${ }^{25,26,27}$. Assuming a relationship between the peak shifts and the adsorption cavity porous diameter, resulting from the shielding effect at the carbon surface, authors have principally investigated the adsorbate behavior in the porosity. Furthermore, in order to improve the spectrum deconvolution, ${ }^{2} \mathrm{H}$ and ${ }^{31} \mathrm{P}$ magic-angle spinning (MAS) NMR techniques have been used to describe multicomponent adsorption phenomena onto activated carbon ${ }^{28,29}$ and to evaluate the effects of carbon substrates activation $^{30}$. The combination of PFG and MAS condition was also carried out, providing diffusion results for liquid crystal confined into microporous glasses ${ }^{31}$.

Studies using ${ }^{1} \mathrm{H}$ MAS NMR in porous carbon have been conducted ${ }^{32}$. Nevertheless, conclusive results remain scarce in the literature for the characterization of the adsorption of organic molecules using NMR methods (quantification of the adsorbed compounds, determination of the diffusion coefficients, characterization of the adsorbed phase for multicomponent adsorption, etc.).

The present work focused on the use of ${ }^{1} \mathrm{H}$ NMR to study the mechanisms of volatile organic compounds adsorbed onto activated carbons. Both ${ }^{1} \mathrm{H}$ MAS NMR and PFG NMR were used to observe and discuss spectral features according to the adsorbate/adsorbent characteristics. In addition, ${ }^{1} \mathrm{H}$ PFG NMR gave selective access to the diffusion coefficients of adsorbed molecules at the micrometer scale $\mathrm{e}^{33,34}$.

\section{MATERIALS AND METHODS}

NMR experiments 
${ }^{1} \mathrm{H}$ MAS NMR was employed to average out chemical shift anisotropies, homonuclear protonproton dipolar coupling and reduce the effect of magnetic susceptibility inhomogeneities. ${ }^{1} \mathrm{H}$ MAS NMR enables the isotropic chemical shifts of adsorbed compounds to be extracted and provides information about their interaction with the carbon surface. Quantitative measurements were carried out using the areas of each peak, taking into account the number of hydrogen atoms, and using a calibration with known quantities of adamantane $\left(\mathrm{C}_{10} \mathrm{H}_{16}\right) .{ }^{1} \mathrm{H}$ NMR spectra were obtained using a BRUKER AV300 (7T) spectrometer with a 4 mm MAS probe. Complementary experiments were performed using a $900 \mathrm{MHz}$ BRUKER spectrometer equipped with a $1.3 \mathrm{~mm}$ MAS probe in order to evaluate the influence of $\mathrm{H}-\mathrm{H}$ dipolar coupling on the proton linewidth.

On the other hand, ${ }^{1} \mathrm{H}$ PFG NMR was used to estimate the self-diffusion coefficients $(D)$, also called the diffusivity, of adsorbed molecules. This technique is based on an echo NMR experiment carried out with a spatial encoding of nuclei. After a diffusion time $(\Delta)$, the magnitude of the sample's signal is measured. Diffusivities are deduced from the correlation between this magnitude and the gradient value ${ }^{35,36}$. Correlatively, the mean squared molecular displacement $(r)$ during the diffusion time $(\Delta)$ is given by the Einstein equation ${ }^{37}$.

$$
r=\sqrt{2 \cdot \Delta \cdot D}(1)
$$

Then, then a molecular velocity $v_{m}$ can be deduced:

$$
v_{m}=\frac{r}{\Delta}
$$

Measurements were performed using a PFGSTE (Pulsed Field Gradient Stimulated Echo) experiment on a BRUKER AV300 spectrometer equipped with a PFG BRUKER probe (30 T/m).

\section{Thermogravimetric analyses (TGA)}


Thermogravimetric measurements were carried out by means of a TA Instrument SDT Q600 analyzer. A loaded sample of THC515 was analyzed at atmospheric pressure under flow of nitrogen. Mass variation was followed versus temperature until $250^{\circ} \mathrm{C}$. At this temperature, for all samples, the mass reached a minimum, which indicated a total desorption of the VOC.

\section{Actived carbon}

A commercial microporous active carbon, reference THC515, produced by Dacarb (Asnièressur-Seine, France) was used. This sorbent is an activated carbon fiber cloth (ACFC). It is particularly suitable for polluted gas treatments. Compared to granular activated carbons, they have larger external surface areas directly linked to nanopores. This specificity leads to a decrease of the intra-particular mass transfer resistance and then to a 2 to 20 times faster adsorption kinetics. Moreover, fast adsorption/desorption cycles using the Joule effect could be easily implemented ${ }^{38}$. BET analysis gave a specific surface area of $1768 \mathrm{~m}^{2} \cdot \mathrm{g}^{-1}$ for THC515. According to the Horvath-Kawazoe (HK) model or the non-linear Density Functional Theory (DFT), the pore width distribution was centered on sizes of $0.46 \mathrm{~nm}$ and $0.49 \mathrm{~nm}$, respectively (Figure 1). Determination of surface functional groups were performed by Boehm'method previously showing weak concentrations (about $0.154 \mathrm{meq} / \mathrm{g}$ for basic group and 0.231 for acid groups $)^{39}$.

\section{Sample preparation}

ACFCs with adsorbed organic compounds were prepared in $2.0 \mathrm{~L}$ glass sealed reactors. Three VOCs were chosen to have a wide range of molecular structures and physical and chemical properties: benzene, cyclohexane and dichloromethane (DCM). Briefly, $100 \mathrm{mg}$ of THC515 was placed in the batch reactor in a central position and a known volume (a few $\mu \mathrm{L}$ ) of liquid VOC 
was injected using a syringe. The adsorption lasted for 48 hours, previously shown to be sufficient to reach equilibrium. The carbon samples were not dried, i.e. directly put into the vessels from the atmosphere, without any drying operation.

\section{RESULTS AND DISCUSSION}

\section{MAS effects}

Figure 2 presents the ${ }^{1} \mathrm{H}$ NMR spectra of benzene, DCM and cyclohexane. A comparison of static and MAS spectra shows the effect of magic-angle spinning on the proton NMR signal. In these three cases, the static peaks exhibit a large magnitude with a correlated much lower full width at half maximum (FWHM) between -4 and $-8 \mathrm{ppm}$. These values are consistent with those of -10 to -6 previously obtained for $\mathrm{H}_{2}$ in a microporous carbon ${ }^{24}$.

In most cases, static NMR linewidths hinder a quantitative analysis of NMR spectra but, as illustrated in Figure 2, magic-angle spinning conditions enhance the detection and enable a clear distinction of VOC signals in the case of multicomponent adsorption. For instance, Figures 2(b) and 2(c) illustrate the value of MAS for spectral analysis. Figure 2(b) represents the NMR spectra of the adsorption of a mixture of cyclohexane/benzene. The MAS signal clearly reveals two separate peaks corresponding to each of the adsorbed molecules. The spectrum in Figure 2(c) was obtained from DCM adsorbed onto a wet host carbon. Water molecules, present in most experiments, and VOC are easily distinguishable and can be quantified. It should also be noted that the spectrum reveals two adsorbed populations of water molecules. This dual peak will be explained below.

\section{Signal broadness interpretation}


The proton NMR signals of VOCs adsorbed onto carbon exhibit some characteristic features of solid state NMR spectra: relatively short attenuation times and a static linewidth of a few kHz (2$4 \mathrm{kHz}$ ). The ${ }^{1} \mathrm{H}$ static NMR linewidth can be explained by different mechanisms: i) homogenous broadening arising from ${ }^{1} \mathrm{H}-{ }^{1} \mathrm{H}$ dipolar interactions, chemical shift anisotropy and a contribution of the $\mathrm{T}_{2}$ relaxation time, ii) inhomogeneous broadening corresponding to a distribution of chemical shifts.

However, the observed ${ }^{1} \mathrm{H}$ NMR linewidth remains relatively small for a real solid state NMR case dominated by homonuclear proton-proton dipolar interactions. One must keep in mind that a proton-proton dipolar interaction for two nuclei separated by one Angstrom gives rise to a dipolar coupling constant of $120 \mathrm{kHz}$. The linewidth measured (a few $\mathrm{kHz}$ ) can probably be explained by two factors: i) a relatively fast and isotropic reorientation of the adsorbed molecules, giving rise to a motional averaging of the dipolar interactions, and ii) the dilution of the molecules on the surface, limiting the possibilities of intermolecular dipolar interactions.

Furthermore, the values of $\mathrm{T}_{2}$ obtained under MAS conditions (about $2 \mathrm{~ms}$ in all cases) suggest that the ${ }^{1} \mathrm{H}$ homogeneous linewidth is only $35 \mathrm{~Hz}$, confirming that the majority of the additional broadening observed in Figures 2(a), 2(b) and 2(c) is a result of a distribution of chemical shifts and, therefore, of chemical environments.

\section{Anisotropy effects}

FWHMs decrease from about $8 \mathrm{ppm}$ of chemical shift in the static case to approximately 1 ppm under MAS conditions (preserving the integrated intensities), confirming the results for comparable spinning rates in a mesoporous carbon ${ }^{32}$. A spinning rate of $10 \mathrm{kHz}$ is high enough 
to average out the spectra anisotropies. A higher spinning rate $(12 \mathrm{kHz}, 15 \mathrm{kHz})$ has no impact on the spectra (no evidence for spinning sidebands or modification of lineshapes).

In addition, a hypothetical broad signal was carefully searched for. Such a signal can be generated by a part of the adsorbed molecules exhibiting large dipolar coupling ${ }^{31,32}$. For this specific purpose, high field ${ }^{1} \mathrm{H}$ NMR recordings correlated with very high MAS frequencies were carried out with the aim of detecting such interaction effects. $15 \mathrm{kHz}, 30 \mathrm{kHz}$ and $45 \mathrm{kHz} \mathrm{MAS}$ signals were recorded on a cyclohexane/THC515 sample using a $900 \mathrm{MHz}$ spectrometer confirming the absence of remaining homonuclear dipolar broadening. The three spectra gave the same integration values.

Therefore, it can be considered that the entire signal was contained in the main NMR peak of the spectra and that MAS frequencies of 10 to $12 \mathrm{kHz}$ were sufficient to average out all the anisotropies fully and reveal completely the signal of all the adsorbed molecules.

Two remarks can be made: i) classic peak integration methods can lead to quantitative measurements (this point was confirmed by a set of thermogravimetric analyses (TGA) whose results differ by less than $10 \%$ relative error from NMR integrations), ii) in terms of diffusometry, classic static PFG measurements can be envisaged.

The relevance of MAS NMR spectroscopy for the quantitative and qualitative analysis of the adsorbed organic compounds in either mono- or multicomponent adsorption was thus confirmed.

\section{Magnetic inhomogeneities (distribution effects)}

The consistent MAS width revealed that the average value of anisotropic bands was not unique, but rather varied from one adsorption site to another. The origin of such fluctuations was explained by the magnetic inhomogeneities in the lattice and a given distribution model was 
proposed. In order to confirm this point, transversal relaxation times $\left(\mathrm{T}_{2}\right)$ were measured. The NMR signal relaxation time is a direct consequence of the defocalization of the set of resonant nuclei. This defocalization is due to two main factors: i) molecular interactions and ii) inhomogeneities of the NMR fields. The latter directly results from the microscopic irregularity of the host lattice and lead to the distribution effect observed on the spectra. The relaxation time of the signal without those inhomogeneities is commonly called the "true $\mathrm{T}_{2}$ " while the real relaxation time measured is called " $\mathrm{T}_{2} *$ ". The presence of inhomogeneities could be observed through a significant difference between $\mathrm{T}_{2} *$ and $\mathrm{T}_{2}$. The classic Spin-Echo measurement method of $\mathrm{T}_{2}$ was used ${ }^{40}$. This pulse sequence leads to the spins refocusing, and does not impact the precession speed, allowing the impact of the magnetic inhomogeneities to be artificially compensated. $\mathrm{T}_{2}$ measurements were carried out on three samples. In all cases, a significant difference (of the order of $1.5 \mathrm{~ms}$ ) was observed between $\mathrm{T}_{2}$ and $\mathrm{T}_{2}{ }^{*}$. Such a discrepancy confirms the large contribution of magnetic inhomogeneities to the observed band width. Overall, the linewidth measured (a few $\mathrm{kHz}$ ) can be explained by two factors: a relatively fast and isotropic reorientation of the adsorbed molecules, giving rise to a motional averaging of the dipolar interactions, and the dilution of the molecules on the surface limiting the possibilities of intermolecular dipolar interactions. Furthermore, the values of $\mathrm{T}_{2}$ obtained under MAS conditions (about $2 \mathrm{~ms}$ in every case) suggest that the ${ }^{1} \mathrm{H}$ homogeneous linewidth is only $35 \mathrm{~Hz}$, confirming that the majority of the additional broadening observed in Figures 2(a), 2(b) and 2(c) is a result of a distribution of chemical shifts and, therefore, of chemical environments.

\section{Distribution effects on NMR signals}


Figures 3 and 4 illustrate the ${ }^{1} \mathrm{H}$ NMR spectra of cyclohexane and DCM adsorbed on THC515, for adsorbed loadings between 0.2 and $4 \mathrm{~mol}_{\mathrm{kg}}{ }^{-1}$. Three features can be noted. Firstly, a significant translation of all signals towards small ppm values was observed, with respect to the chemical shifts of the same molecule in liquid form. Interestingly, this difference clearly changes from one compound to another. Chemical shifts were decreased by $7 \mathrm{ppm}$ for cyclohexane, 10 ppm for DCM, and 6 ppm for water. This shift was $5.5 \mathrm{ppm}$ for benzene (Figure 2). Secondly, these shifts were dependent on the adsorbed amounts. For the three VOCs, higher amounts were associated with an enlargement towards high ppm values, which induced a shift of approximately $1 \mathrm{ppm}$ of the MAS averaged signal. This phenomenon was already obtained on mesoporous and microporous carbons ${ }^{32,24}$. Thirdly, for increasing loadings of VOCs, the initial adsorbed water signal vanished while a new peak located a few ppm away appeared. The origin of lineshape modifications can be related to the population of various sites presenting unequal interactions with the molecules. The magnetic field experienced by the nucleus corresponded to the applied NMR, slightly impacted by the shielding effect produced by the magnetic susceptibility at the carbon surface $^{41,42,43}$. A classic interpretation of this phenomenon can be provided. The induced field is caused by the ring currents generated by the $\pi$ electrons of the graphite layers. Since it goes against the excitation (Lenz's law), the actual field experienced by the absorbed nucleus above the graphitic plane is lower than the original NMR field ${ }^{44}$. For the storage of hydrogen in porous carbons, a phenomenological model to interpret chemical shift corrections $(\Delta \delta)$ in graphitic cavities has been proposed ${ }^{24}$. According to this approach, the impact of a graphitic plane on the chemical shift at the vicinity of the surface is described by Equation (3):

$$
\Delta \delta=\frac{a}{d^{3}}
$$


where $(d)$ is the distance to the plane and $(a)$ is a constant depending on the magnetic moment of the adsorbent layer. Such a surface is highly anisotropic and gives rise to a strong modification of the adsorbed molecule chemical shift tensor.

Its correction to the applied field is given by Equation (4) proposed by Carrington ${ }^{45}$.

$$
\Delta \sigma=-\frac{\mu_{0}}{4 \pi} \cdot \frac{e^{2} \cdot R^{2}}{\sqrt{2} \cdot m_{e}} \cdot \frac{1}{d^{3}}
$$

where $e$ is the elementary charge, $m_{e}$ the electron mass, $R$ the ring current radius and $\mu_{0}$ the magnetic constant. Finally, taking into account two parallel walls in a slit pore of width $w$ gives:

$$
\Delta \delta=a\left(\frac{1}{d^{3}}+\frac{1}{(w-d)^{3}}\right)
$$

Considering a proton located in the middle of the cavity:

$$
\Delta \delta=\frac{16 a}{w^{3}}
$$

At a microscopic level, theoretical calculations show the most energetically favorable position for benzene adsorbed on a graphene sheet. These studies depict a molecular plane strictly parallel to the graphene layer and give an equilibrium separation of $0.36 \mathrm{~nm}$ between the benzene and graphitic planes ${ }^{46,47,48}$. Therefore, in a pore thinner than $0.72 \mathrm{~nm}$ in the case of monolayer adsorption, the molecule is considered to be at the center of the cavity.

According to the textural characterization, a narrow pore distribution was observed for THC515, with micropore sizes centered at $0.45 \mathrm{~nm}$. On the basis of this value, using Equation (4), the $a$ value was calculated at $-0.031 \mathrm{ppm} . \mathrm{nm}^{3}$. This approach, despite its phenomenological character, allows the shift dependence of the molecules with respect to the pore diameter to be calculated.

However, several observations can be made from Figures 5 and 6. Figure 5 shows that slitshaped pores with widths between 0.43 and $0.49 \mathrm{~nm}$ are involved in benzene adsorption 
phenomena. This interval perfectly matches the BET pore size distribution peak of THC515 (shown in Figure 1 using the Horvath-Kawazoe model). The observed experimental shifts, between -4 and -7 ppm, can be converted into a pore size by applying Equation (5). Figure 5 shows that the ${ }^{1} \mathrm{H}$ spectra are related to pore sizes between 0.43 and $0.49 \mathrm{~nm}$.

Furthermore, the NMR peak enlargement towards high values of ppm proves that small cavities are favored during the adsorption process. However, a limitation occurred for ultramicropores, with a diameter less than $0.4 \mathrm{~nm}$. The minimum shift values observed for $\mathrm{C}_{6} \mathrm{H}_{6}$ were of the order of $-7 \mathrm{ppm}$. Therefore, there is no experimental evidence for the occupation of pores smaller than $0.4 \mathrm{~nm}$. The $10 \mathrm{ppm}$ case of DCM results from geometrical factors. For a given pore size, a proton from DCM will be located closer than $\mathrm{C}_{6} \mathrm{H}_{6}$, leading to a strong ${ }^{1} \mathrm{H}$ shift. Figure 7 shows the shift of non-centered protons. Independently of slit size, it appears that for a wall/proton distance less than $0.15 \mathrm{~nm}$, the shift was clearly higher than $10 \mathrm{ppm}$. Consequently, it may also be anticipated that for micropores thinner than 0.5 to $0.6 \mathrm{~nm}$, multilayer adsorption was unlikely. The conformations of cyclohexane suggested higher fluctuations of chemical shifts. The spectra gave a value of $7 \mathrm{ppm}$, which was less than the shift measured for dichloromethane. The steric congestion of cyclohexane may explain its adsorption in larger pores than benzene or dichloromethane molecules (Figure 7).

\section{VOC adsorption and water desorption mechanisms}

The adsorption competition of water/VOC was well described by MAS NMR. Figure 3(a) shows the water peak of spectra recorded with increasing amounts of adsorbed dichloromethane. Water is gradually desorbed from the micropores revealing a preferential adsorption of VOC in micropores. Such a phenomenon was also observed onto micro/macroporous carbon by Gun'ko 
et al. (2008) for a water/benzene mixture ${ }^{19}$. Interestingly, the initial water peak magnitude continuously decreased and was gradually replaced by another one with a chemical shift of -0.5 ppm and increasing intensity. The $-0.5 \mathrm{ppm}$ chemical shift of the new peak remained much lower than that of liquid water, revealing a weaker but still significant influence of the graphitic network. Thus, the presence of adsorbed water inside the microporosity was still assumed, with a decrease in the wall $/ \mathrm{H}_{2} \mathrm{O}$ molecule interaction. In other terms, migration of $\mathrm{H}_{2} \mathrm{O}$ towards larger micropores and/or mesopores was revealed. In addition, the very flat component appearing in Figure 3(d)/curve (d) could be attributed to residual extra-porous adsorbed water. PFG measurements in the next section of this work completed and confirmed this competition behavior involving water and $\operatorname{VOC}(\mathrm{s})$.

\section{Measurement of self-diffusion constants}

PFG recordings were conducted on wet THC515 with three VOCs for various diffusion time $\Delta$ values (from $40 \mathrm{~ms}$ to $180 \mathrm{~ms}$ ). Measurements were limited to $180 \mathrm{~ms}$ due to the $\mathrm{T}_{2}$ relaxation effect. Over this period, the signal/noise ratio was too weak. Figure 8 shows the cylcohexane $\Psi / \Psi^{\circ}$ ratio evolution for increasing gradient intensities for $\Delta=80 \mathrm{~ms}$. Experimental and fitted model curves are presented. The commonly used model equation is:

$$
\frac{\Psi}{\Psi_{0}}=\sum_{i} p_{i} \cdot \exp \left[-\gamma^{2} \cdot G^{2} \cdot \delta^{2} \cdot D_{s, i} \cdot\left(\Delta-\frac{\delta}{3}\right)\right]
$$

Equation (6) involves many groups of molecules with self-diffusion $\mathrm{D}_{\mathrm{s}, \mathrm{i}} \cdot p_{\mathrm{i}}$ is the fraction of molecules in group $i, \gamma$ the proton gyromagnetic ratio, $\mathrm{G}$ the applied magnetic field gradient and $\delta$ the pulse duration.

In porous systems, the diffusivity is generally given by ${ }^{49}$ : 


$$
D_{s}=p_{a d s} . D_{s, a d s}+p_{v} . D_{s, v}
$$

Where $p_{a d s}$ and $D_{s, a d s}$ are respectively the fraction and the self-diffusion constant of adsorbed molecules, and $p_{v}$ and $D_{s, v}$ respectively the fraction and the self-diffusion of molecules in the vapor phase in equilibrium with the adsorbed one.

The agreement between the model and measurements was obtained using a single diffusivity value. Consequently, a single dominant diffusion phenomenon was implied. According to the wall/nucleus distance previously evaluated, and the unique peak obtained in MAS spectra, the dominant diffusion mechanism was expected to be surface diffusion. Consequently, $p_{v}$ can be considered negligible.

Three diffusion mechanisms are involved in porous structures and their respective predominance depends on both pore size and the molecule free mean path (FMP) $)^{50}$. But, it should be noted that FMP must be distinguished from the molecular displacements below deduced from PFG experiments. FMP corresponds to the mean distance covered by a molecule between two collisions with another molecule. If the pore diameter is larger than the FMP, collisions with walls are not influential and a molecular diffusion process is predominant. If the FMP increases or the pore size is smaller, the host frame presence appears in the diffusion process. The contribution of wall collisions becomes significant and Knudsen's diffusion mechanism is then effective. Lastly, if the FMP is of the same order as the pore diameter, the wall/molecule interaction is dominant and the surface diffusion mechanism is expected ${ }^{44}$. Modeling has provided orders of magnitude of $D_{s}$ for these diffusion processes ${ }^{51,52,53}$. In nanopores $(<2 \mathrm{~nm})$, surface diffusion is largely dominant with $\mathrm{D}_{\mathrm{s}}$ values lower than $10^{-8} \mathrm{~m}^{2} \cdot \mathrm{s}^{-1}$. For cyclohexane, a $D_{s}$ of the order of $4.10^{-12} \mathrm{~m}^{2} \cdot \mathrm{s}^{-1}$ was measured. $D_{s} \approx 1.10^{-11} \mathrm{~m}^{2} \cdot \mathrm{s}^{-1}$ and $D_{s} \approx$ $4.10^{-11} \mathrm{~m}^{2} \cdot \mathrm{s}^{-1}$ were obtained for benzene and DCM, respectively. Those values were in agreement 
with those of $10^{-10} \mathrm{~m}^{2} \cdot \mathrm{s}^{-1}$ to $5.10^{-9} \mathrm{~m}^{2} \cdot \mathrm{s}^{-1}$ in studies carried out for cyclohexane onto actived carbon micro-meso hierarchical pore systems ${ }^{54}$ and hexane in MCM-41 mesoporous silicas ${ }^{55}$. In addition, they confirmed the cyclohexane MAS results. In fact, the lower diffusivity of cyclohexane corroborated the previous assumption of its reduced mobility in porosity as this molecule has a more complex and voluminous structure.

Diffusivities $D s$ and corresponding molecular velocities are reported in Figure 8. A slight decrease in these parameters is observed with the observation time. This feature is explained by a short $\Delta$ time with respect to the time interval between two redirections of diffusing molecules in the host frame. The phenomenon is illustrated considering the molecule displacement in Figure 9. This schematic presentation demonstrates that with a short $\Delta$, the measured molecular displacement doesn't take account of the redirection phenomenon and, as a result, provides $v_{m}$ and $D_{s}$ values greater than the macroscopic one. Using a sufficiently long $\Delta$, the mean number of redirections per time unit becomes constant, and the limit values of $D_{s}$ and $v_{\mathrm{m}}$ are reached. Interestingly, in the latter conditions, the NMR diffusion coefficient value leads to the diffusivity that could be observed at a macroscopic scale.

\section{Confirmation of water behavior}

Two sets of recording were carried out on wet THC515. The first sample contained only adsorbed water $\left(4\right.$ mol. $\left.\mathrm{kg}^{-1}\right)$ while the second was loaded with a water/cyclohexane mixture. Adsorbed water concentration was also of the order of 4 mol. $\mathrm{kg}^{-1}$ and cyclohexane was doubly deuterated $\mathrm{C}_{6} \mathrm{D}_{12}$. Consequently, only adsorbed water molecules were analyzed by NMR. The ${ }^{1} \mathrm{H}$ MAS spectra of these samples are shown in the inset of Figure 10. The change in water molecule behavior was thus highlighted. 
The $D_{s}$ values from PFG measurements were of the order of $5.10^{-13} \mathrm{~m}^{2} . \mathrm{s}^{-1}$ for the first sample (water only) and $10^{-11} \mathrm{~m}^{2} \cdot \mathrm{s}^{-1}$ for the second (water/deuterated cyclohexane). The ratio of 50 between the two $D_{s}$ values remained constant despites $\Delta$ variations. Figure 10 represents the molecular velocities values and their constant ratio. It reveals a six times higher water mobility in the presence of VOC. The results obtained using MAS NMR were thus confirmed. A lower interaction with the host frame induced both a lower peak shift towards strong fields and a greater mobility. Nevertheless, these $D_{s}$ values verified that surface diffusion was occurring, excluding the assumption of extra-porous water and confirming the dual presence of water and VOC in micropores.

\section{CONCLUSION}

The possibility of using ${ }^{1} \mathrm{H}$ NMR as a tool for the detection, identification and quantification of VOCs adsorbed onto wet ultra-microporous activated carbon has been assessed. Under static conditions, water, cyclohexane, benzene and DCM gave rise to very wide signals (several tens of ppm) significantly shifted towards low ppm values (5 to $10 \mathrm{ppm}$ ) compared to the chemical shifts of the liquid solutions of these compounds. The origin of the spectral width of the recorded peaks could be attributed to the combination of very low transversal relaxation time values, strong chemical shift anisotropy effects and homonuclear dipolar interactions. The latter averaged under MAS conditions gave spectral bandwidths as small as $1 \mathrm{ppm}$, thus allowing the separation and identification of each VOC signal. Furthermore, resorting to a semi-empirical model enabled the averaged chemical shifts to be linked to the magnetic effects of the carbon walls and therefore to the resonating proton/pore wall distance. Thus, despite the short signal attenuation time, PFG studies could be carried out for diffusion times reaching $40 \mathrm{~ms}$. This study 
showed diffusion coefficients tending towards a constant value, revealing the macroscopic aspect of the diffusion phenomenon. These results suggest the possibility of obtaining exploitable values in the current kinetic models of mass transfer in porous materials. The use of various techniques of solid state NMR, including Magic Angle Spinning, Pulsed Field Gradient and even Magnetic Resonance Imaging, applied to the study of small molecule interactions with carbon surfaces constitutes a rapidly growing field of research. So far, NMR studies focusing on the application for supercapacitors are the most advanced ${ }^{56},{ }^{57}, 58,{ }^{59}$ (ref, x, y, z, t) but, as shown in this paper, we believe this combination of NMR techniques constitutes also a very promising tool for studying the VOC adsorption onto activated carbons. 


\section{List of figures}

Figure 1. THC515 pore width distribution (HK method). Inset: scanning electronic microscopy (SEM) pictures of THC515.

Figure 2. Static and MAS (9 kHz) spectra on THC515: (a) benzene (2.0 mol. $\left.\mathrm{kg}^{-1}\right)$; (b) mixture of benzene $\left(2.0\right.$ mol. $\left.\mathrm{kg}^{-1}\right) /$ cyclohexane $\left(1.2\right.$ mol. $\left.\mathrm{kg}^{-1}\right)$; (c) dichloromethane (DCM) (2.5 mol. $\left.\mathrm{kg}^{-1}\right) /$ water $\left(2.3 \mathrm{~mol} . \mathrm{kg}^{-1}\right)$.

Figure 3. (3a) ${ }^{1} \mathrm{H}$ MAS spectra (spinning rate $9 \mathrm{kHz}$ ). Spectra of cyclohexane adsorbed onto non-dried THC515 for various loadings; (a) $0.2 \mathrm{~mol} . \mathrm{kg}^{-1}$, (b) $0.7 \mathrm{~mol} . \mathrm{kg}^{-1}$, (c) $2.5 \mathrm{~mol} . \mathrm{kg}^{-1}$, (d) 4.0 mol. $\mathrm{kg}^{-1}$. Fig. (3b) represents high ppm values of the spectra, containing the water molecule signals.

Figure 4. MAS $9 \mathrm{kHz}$ spectra of DCM adsorbed onto non-dried THC515 for various loadings; (a) 0.1 mol. $\mathrm{kg}^{-1}$, (b) $0.4 \mathrm{~mol} . \mathrm{kg}^{-1}$, (c) $1.7 \mathrm{~mol} . \mathrm{kg}^{-1}$, (d) $3.3 \mathrm{~mol} . \mathrm{kg}^{-1}$. Figure (4b) represents the DCM (dichloromethane) parts of these spectra.

Figure 5. Correlation between the pore width and the NMR shift according to Equation (3). Figure 6. Correlation between the wall/nucleus distance in different porous cavities according to (3); (a) $0.5 \mathrm{~nm}$; (b) $0.44 \mathrm{~nm}$; (c) $0.40 \mathrm{~nm}$.

Figure 7. Illustrations of H/wall distance for benzene, DCM and cyclohexane molecules, respectively.

Figure 8. NMR echo intensity with respect to the gradient for $\Delta=80 \mathrm{~ms}$. Inset: diffusivity $D_{s}$ and molecular velocity with respect to the diffusion time $\Delta$.. 
Figure 9. Illustration of the evolution of the real displacement / measured displacement ratio with various values of diffusion times.

Figure 10. Measured $\mathrm{H}_{2} \mathrm{O}$ Molecular velocities $v_{\mathrm{m} 1}$ (only $\mathrm{H}_{2} \mathrm{O}$ loaded) and $v_{\mathrm{m} 2}$ (mixture $\mathrm{H}_{2} 0 / \mathrm{C}_{6} \mathrm{D}_{12}$ loaded) with respect to the observation time $\Delta$. Inset : MAS $9 \mathrm{kHz}$ spectra of THC515 loaded with $\mathrm{H}_{2} \mathrm{O}$ and a mixture of $\mathrm{H}_{2} \mathrm{O} / \mathrm{C}_{6} \mathrm{D}_{12}$ (dashed line). 


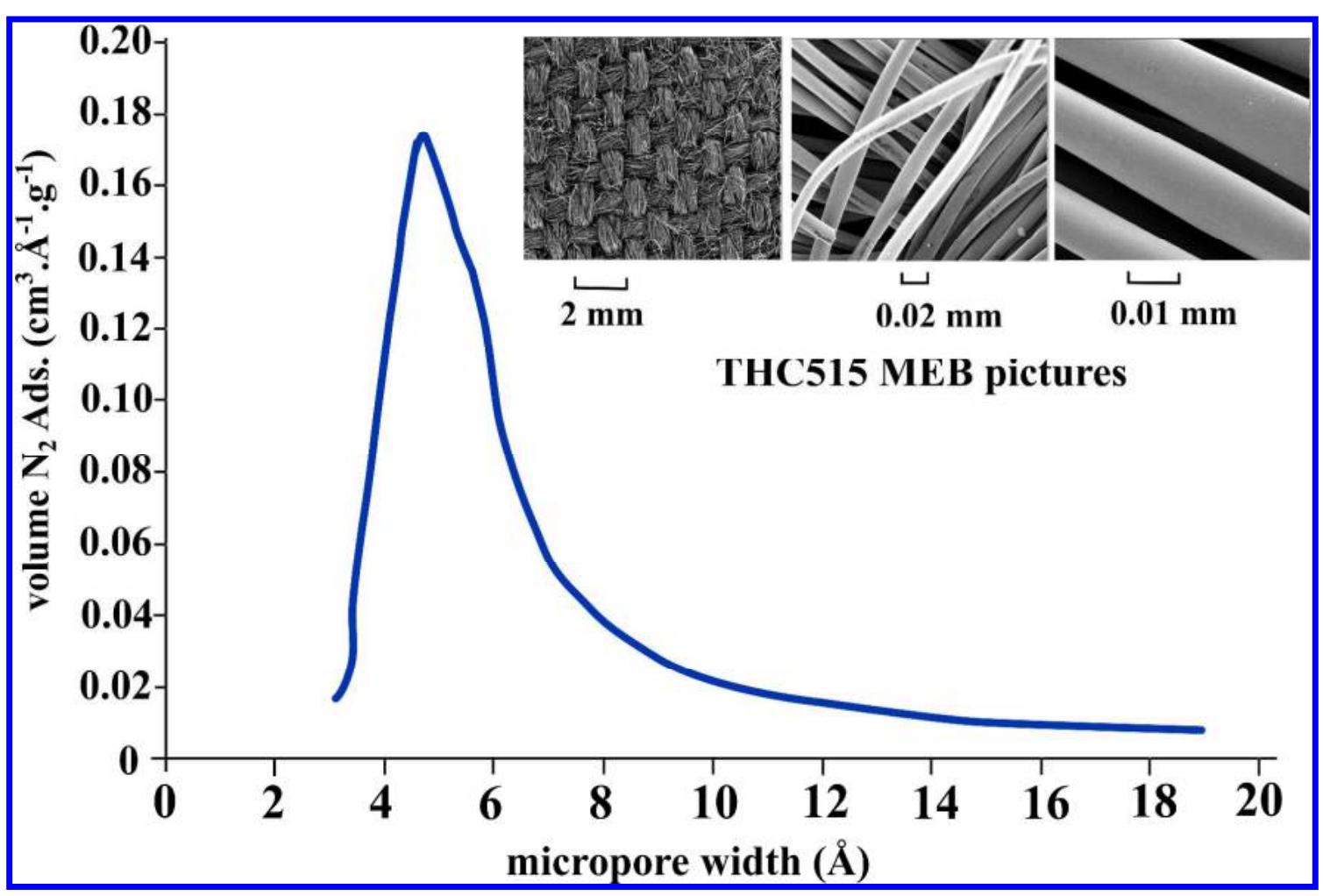

Figure 1. THC515 pore width distribution (HK method). Inset: scanning electronic microscopy (SEM) pictures of THC515. 

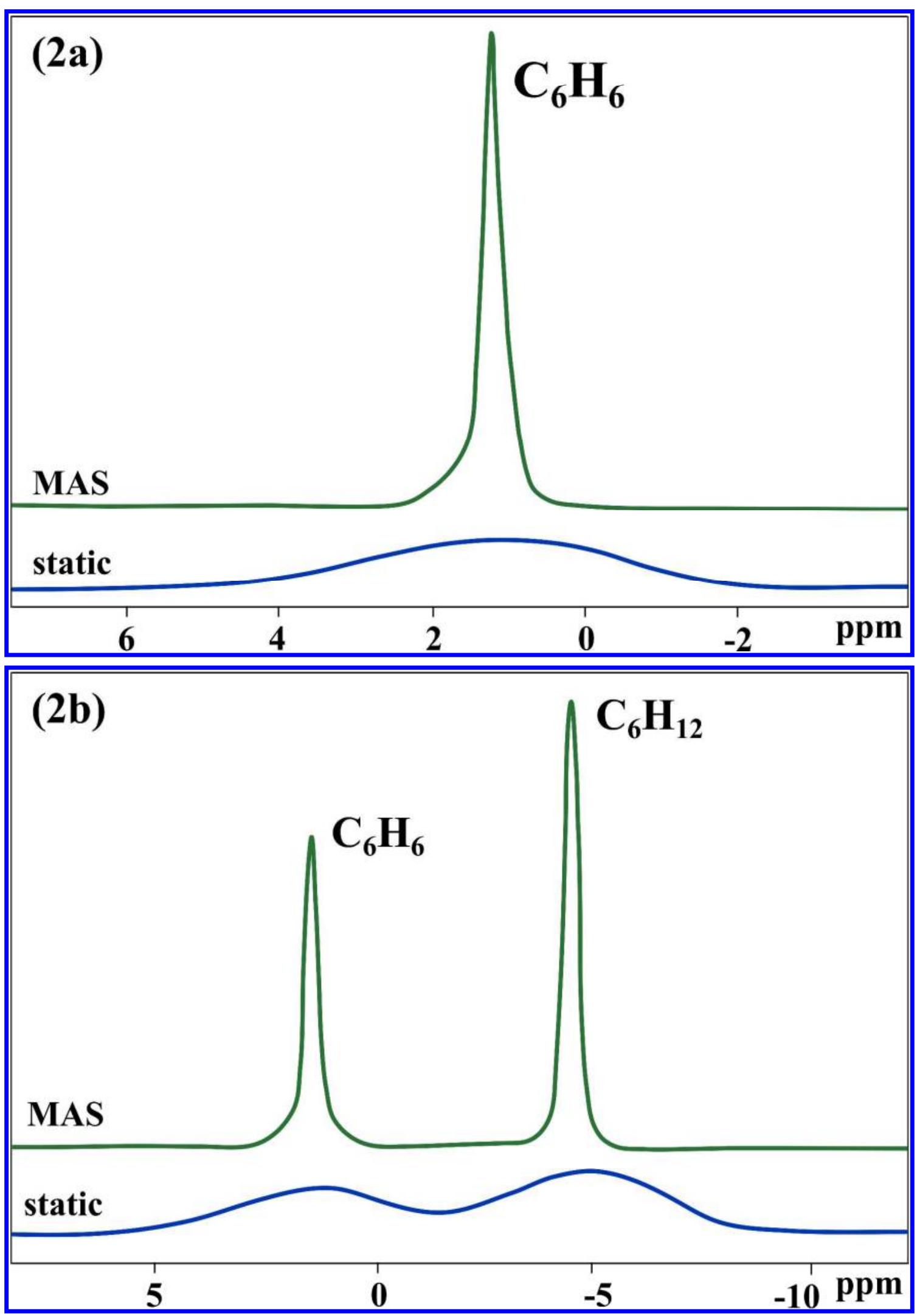

ACS Paragon Plus Environment 


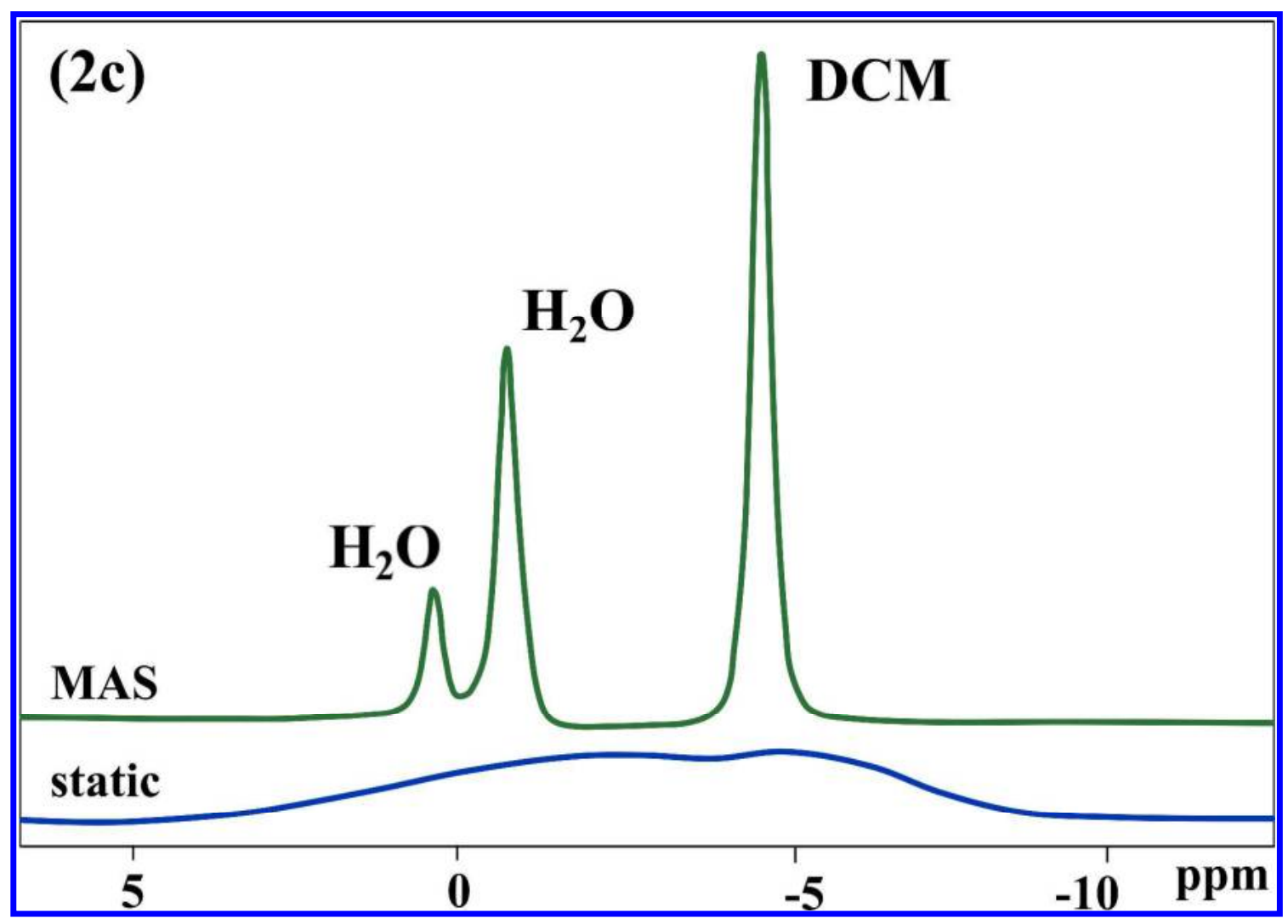

Figure 2. Static and MAS (9 kHz) spectra on THC515: (a) benzene $\left(2.0 \mathrm{~mol} . \mathrm{kg}^{-1}\right)$; (b) mixture of benzene $\left(2.0 \mathrm{~mol} . \mathrm{kg}^{-1}\right) /$ cyclohexane $\left(1.2 \mathrm{~mol} . \mathrm{kg}^{-1}\right)$; (c) dichloromethane (DCM) (2.5 mol. $\mathrm{kg}^{-}$ $\left.{ }^{1}\right) /$ water $\left(2.3 \mathrm{~mol} \cdot \mathrm{kg}^{-1}\right)$. 

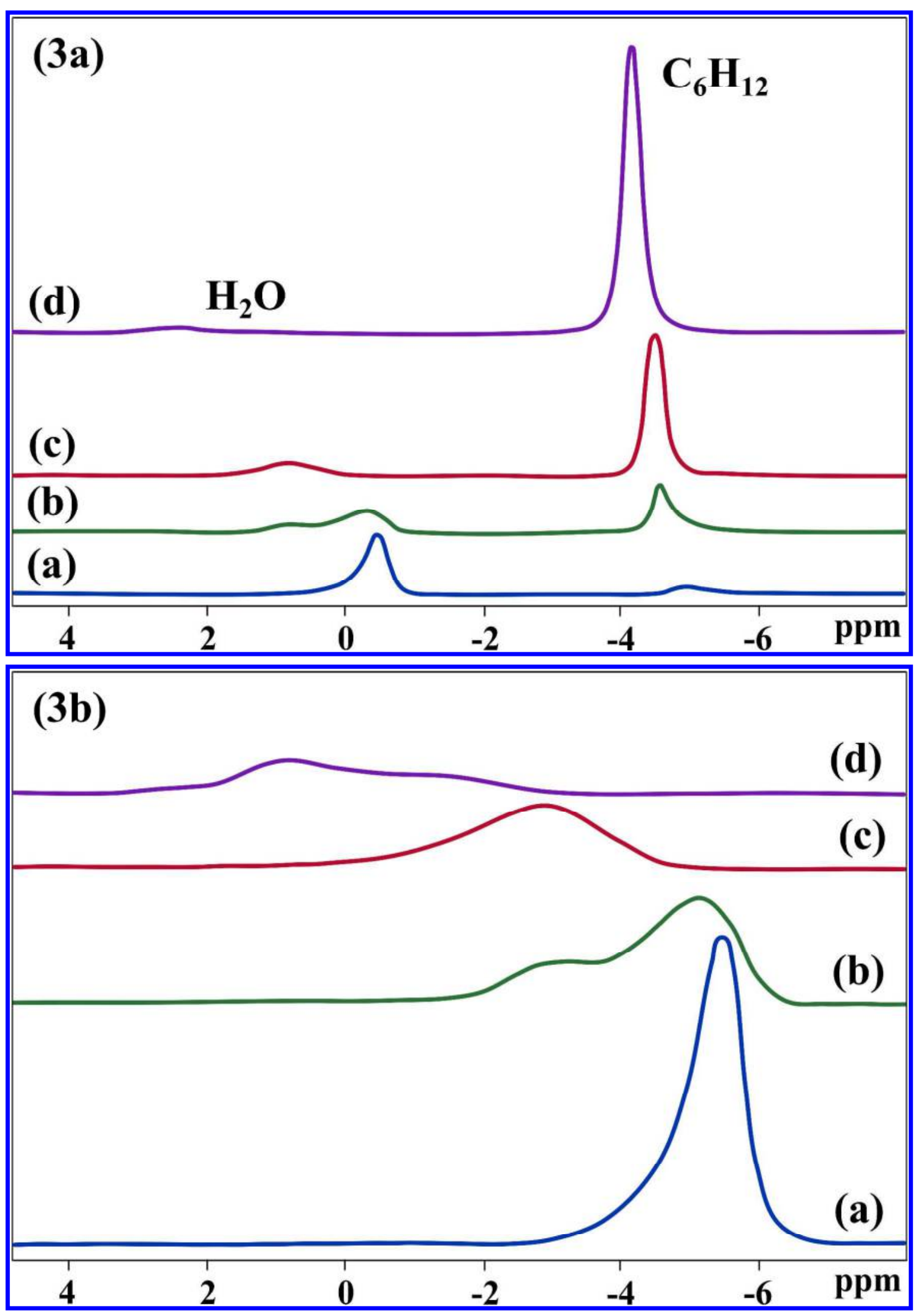

ACS Paragon Plus Environment 
Figure 3. (3a) ${ }^{1} \mathrm{H}$ MAS spectra (spinning rate $9 \mathrm{kHz}$ ). Spectra of cyclohexane adsorbed onto non-dried THC515 for various loadings; (a) 0.2 mol. $\mathrm{kg}^{-1}$, (b) $0.7 \mathrm{~mol} . \mathrm{kg}^{-1}$, (c) $2.5 \mathrm{~mol} . \mathrm{kg}^{-1}$, (d) 4.0 mol. $\mathrm{kg}^{-1}$. Fig. (3b) represents high ppm values of the spectra, containing the water molecule signals.

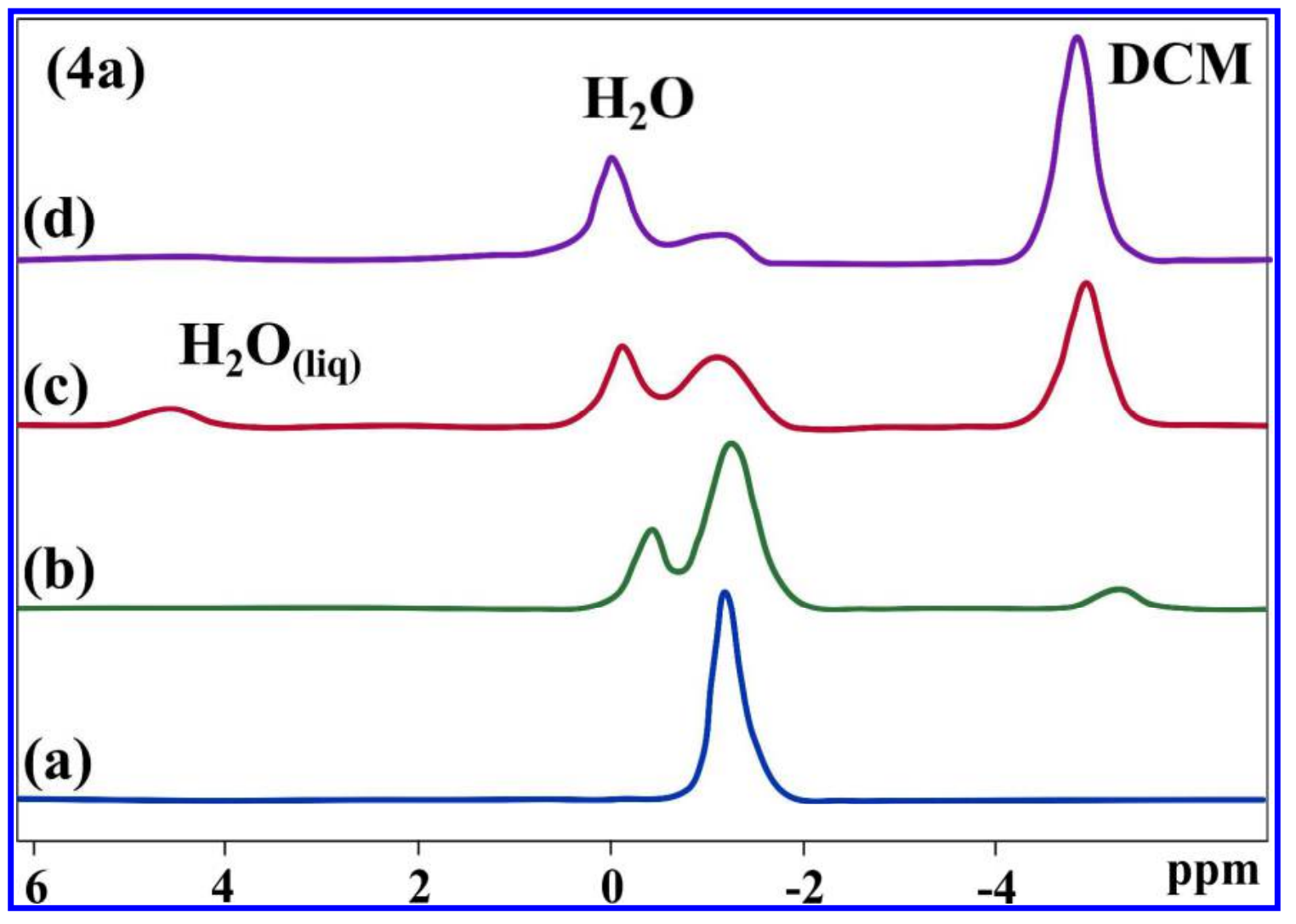




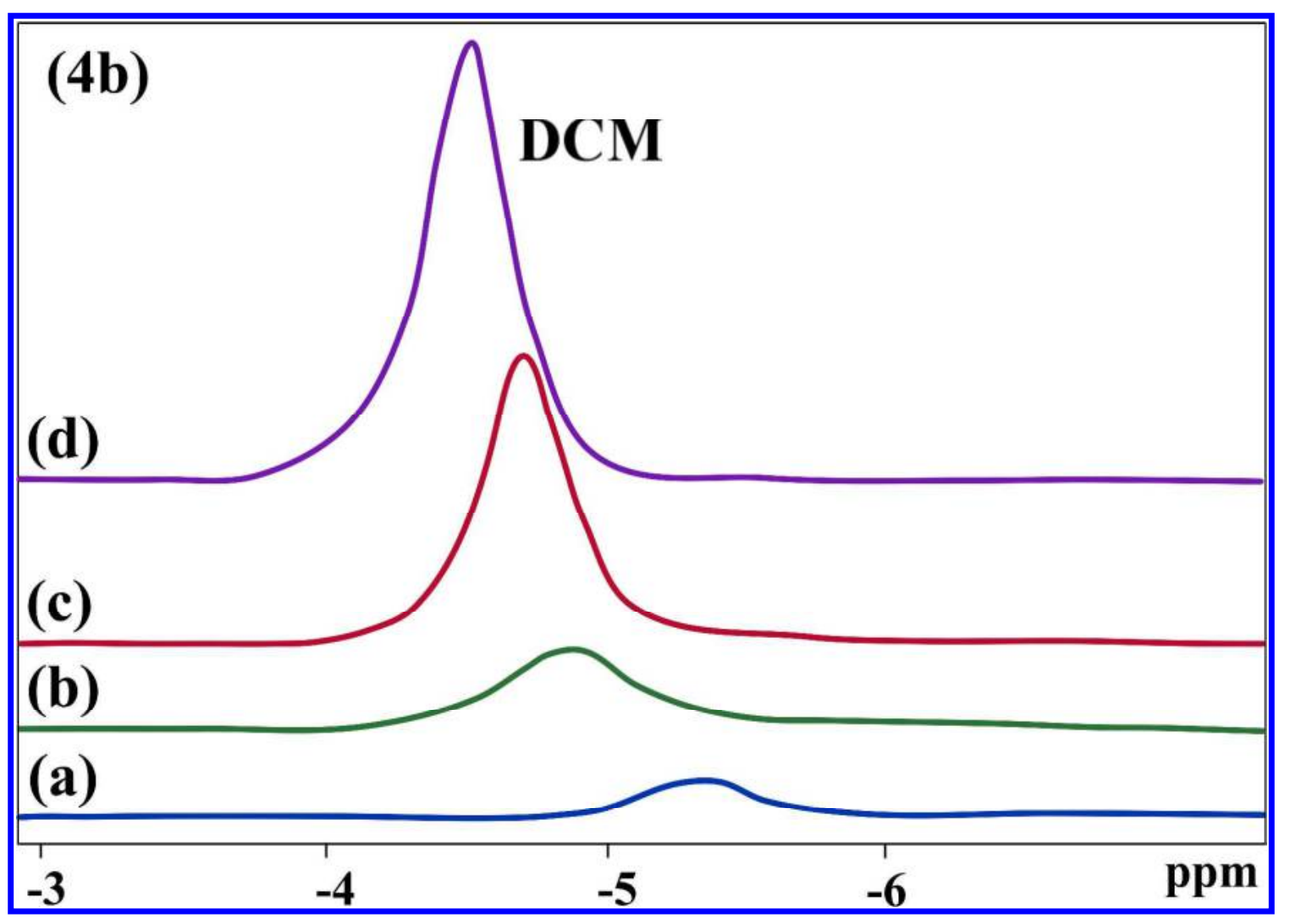

Figure 4. MAS $9 \mathrm{kHz}$ spectra of DCM adsorbed onto non-dried THC515 for various loadings;

(a) 0.1 mol. $\mathrm{kg}^{-1}$, (b) $0.4 \mathrm{~mol} . \mathrm{kg}^{-1}$, (c) $1.7 \mathrm{~mol} . \mathrm{kg}^{-1}$, (d) $3.3 \mathrm{~mol} . \mathrm{kg}^{-1}$. Figure (4b) represents the DCM (dichloromethane) parts of these spectra. 


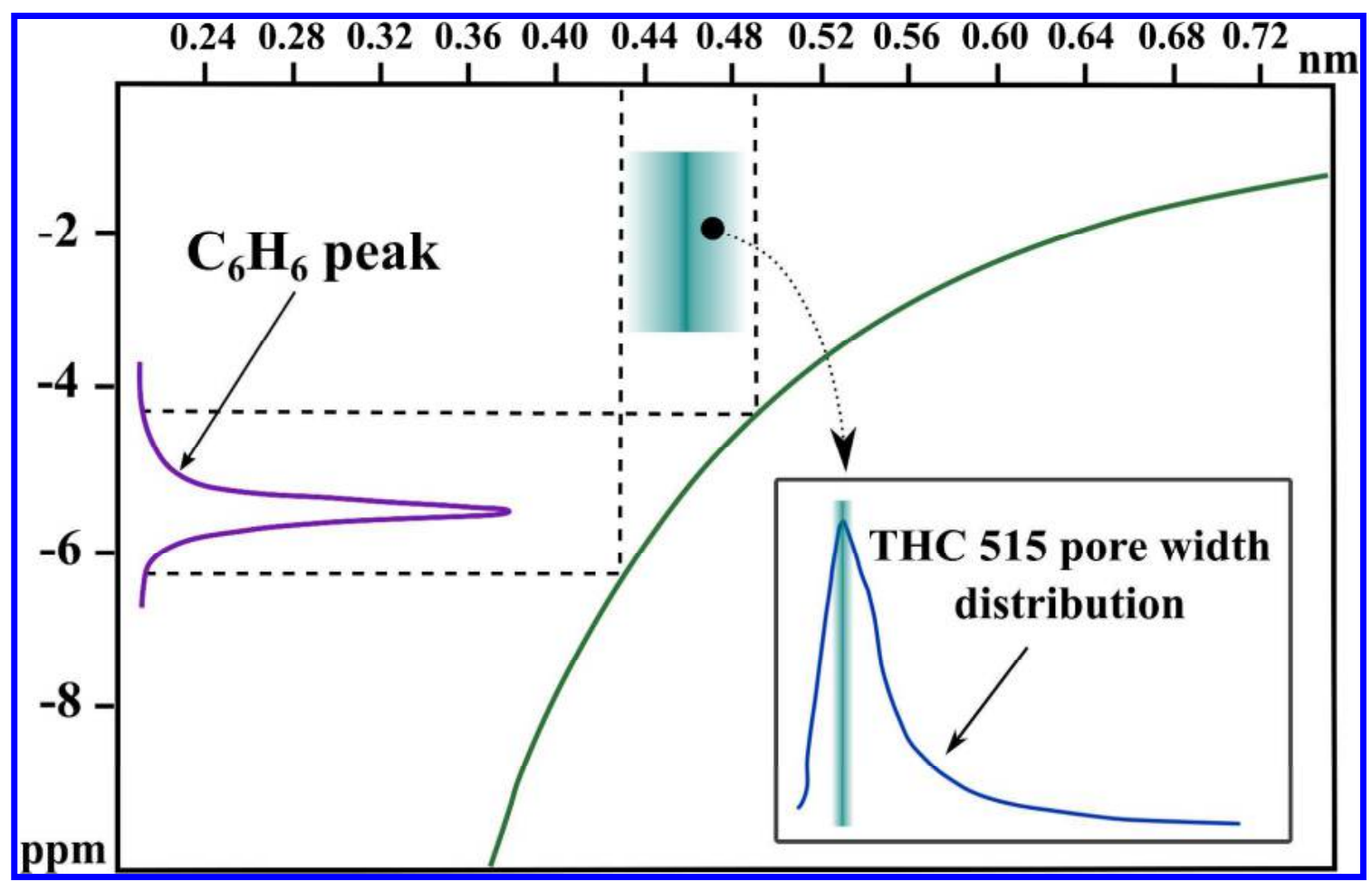

Figure 5. Correlation between the pore width and the NMR shift according to Equation (3). 


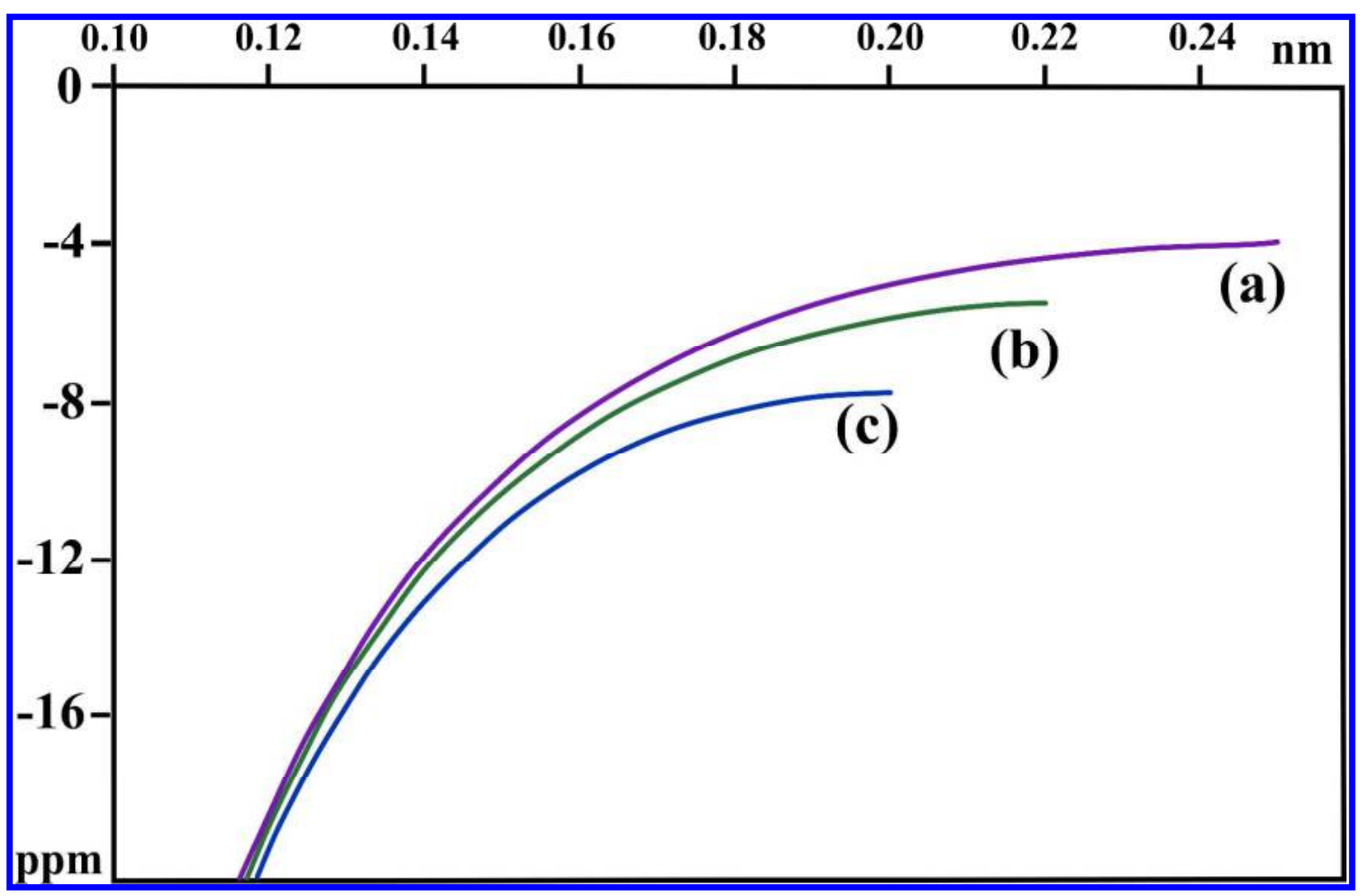

Figure 6. Correlation between the pore wall/nucleus distance in different porous cavities according to Equation (3). (a) $0.5 \mathrm{~nm}$; (b) $0.44 \mathrm{~nm}$; (c) $0.40 \mathrm{~nm}$. 


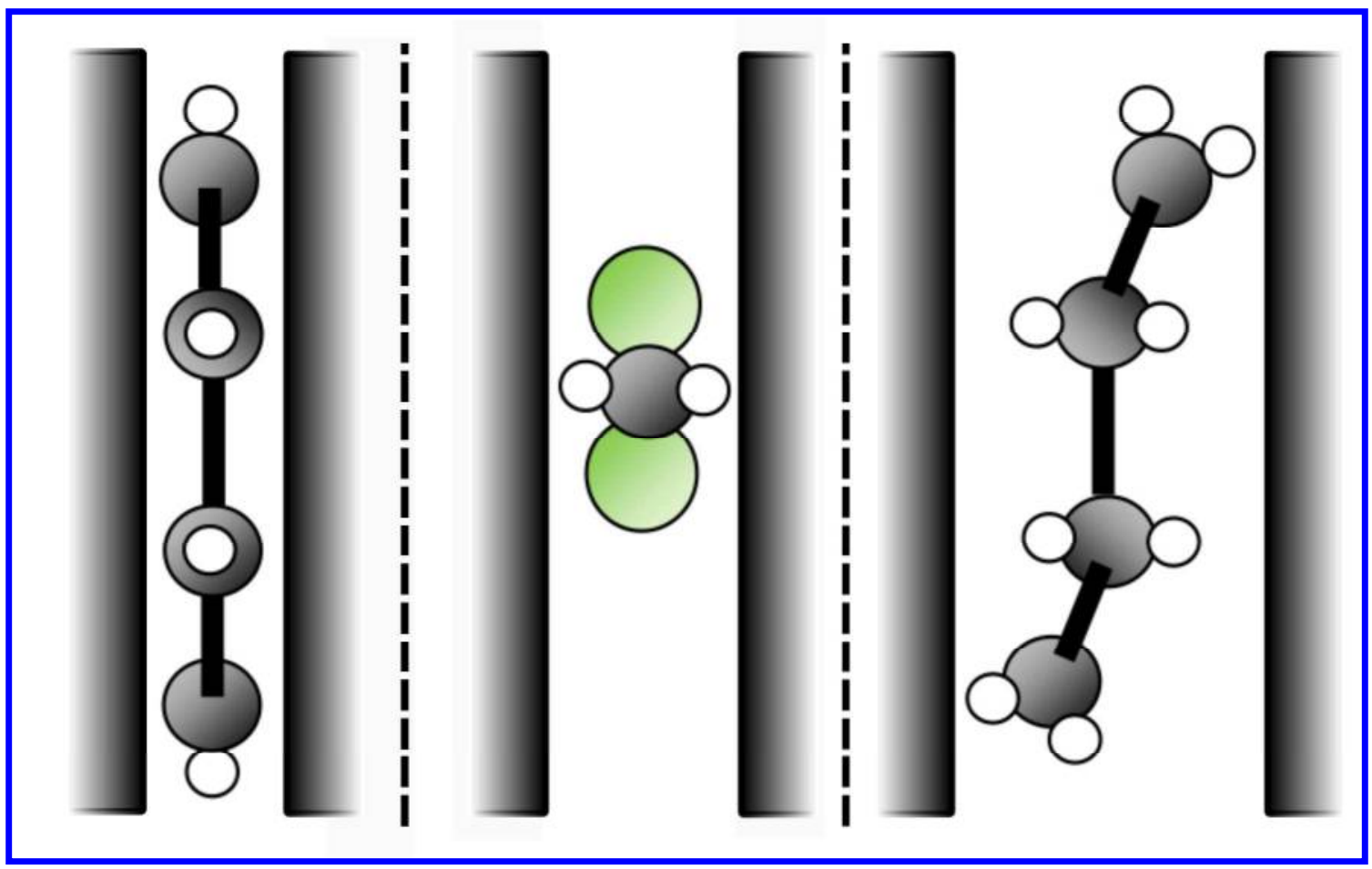

Figure 7. Illustrations of $\mathrm{H} /$ wall distance for benzene, DCM and cyclohexane molecules, respectively. 


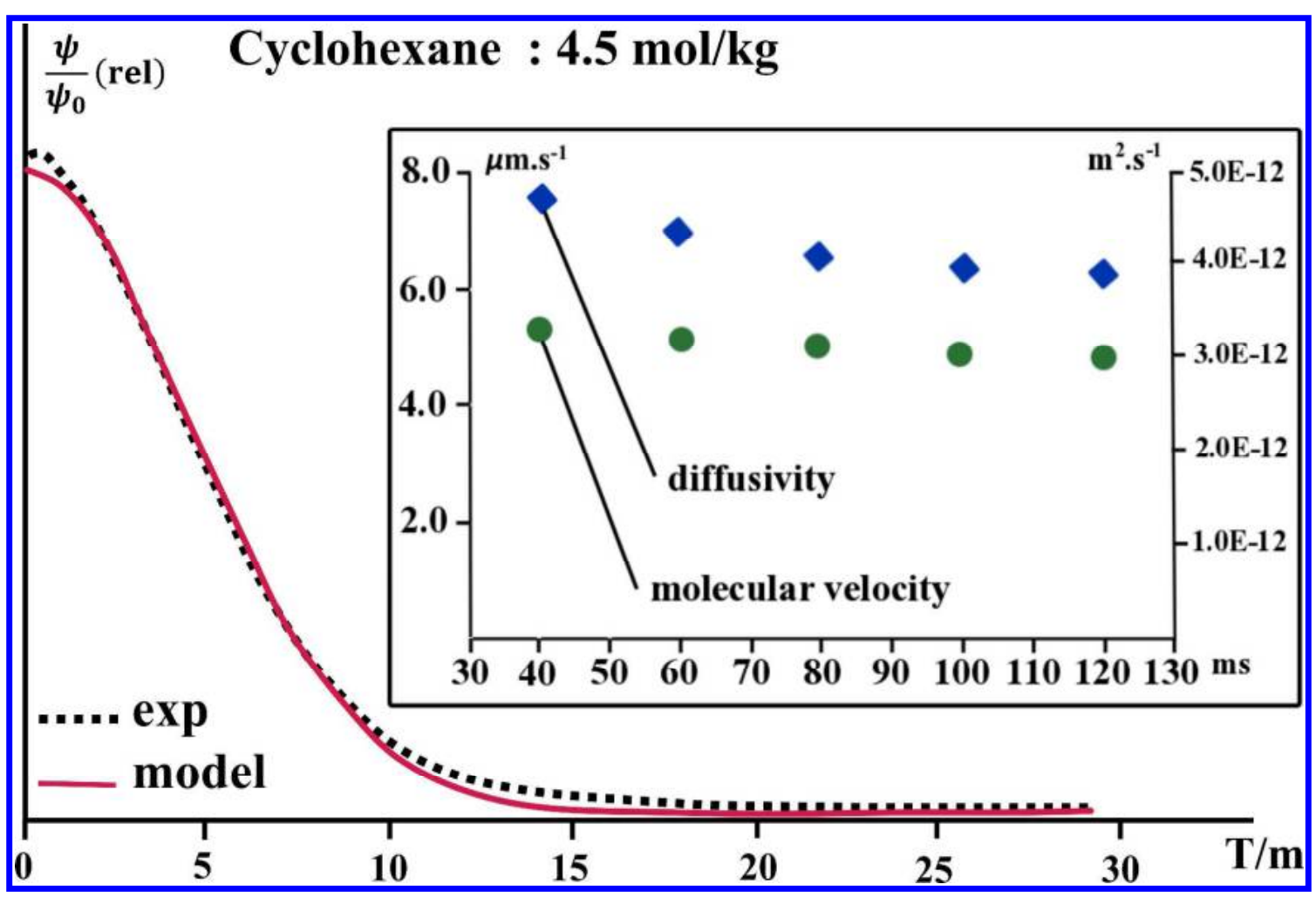

Figure 8. NMR echo intensity with respect to the gradient for $\Delta=80 \mathrm{~ms}$. Inset: diffusivity $D_{s}$ and molecular velocity with respect to the diffusion time $\Delta$. 


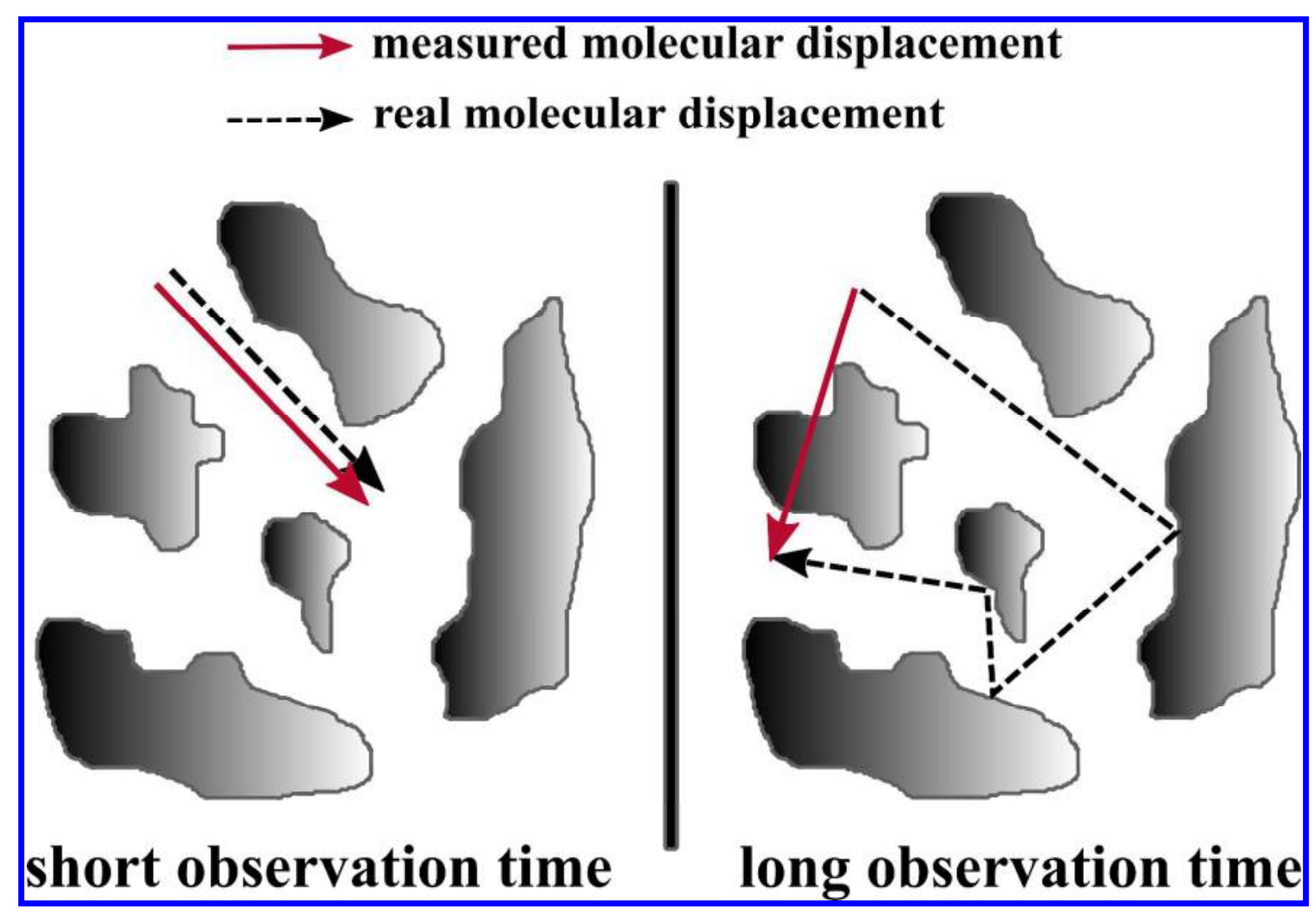

Figure 9. Illustration of the evolution of the real displacement / measured displacement ratio with various values of diffusion times. 


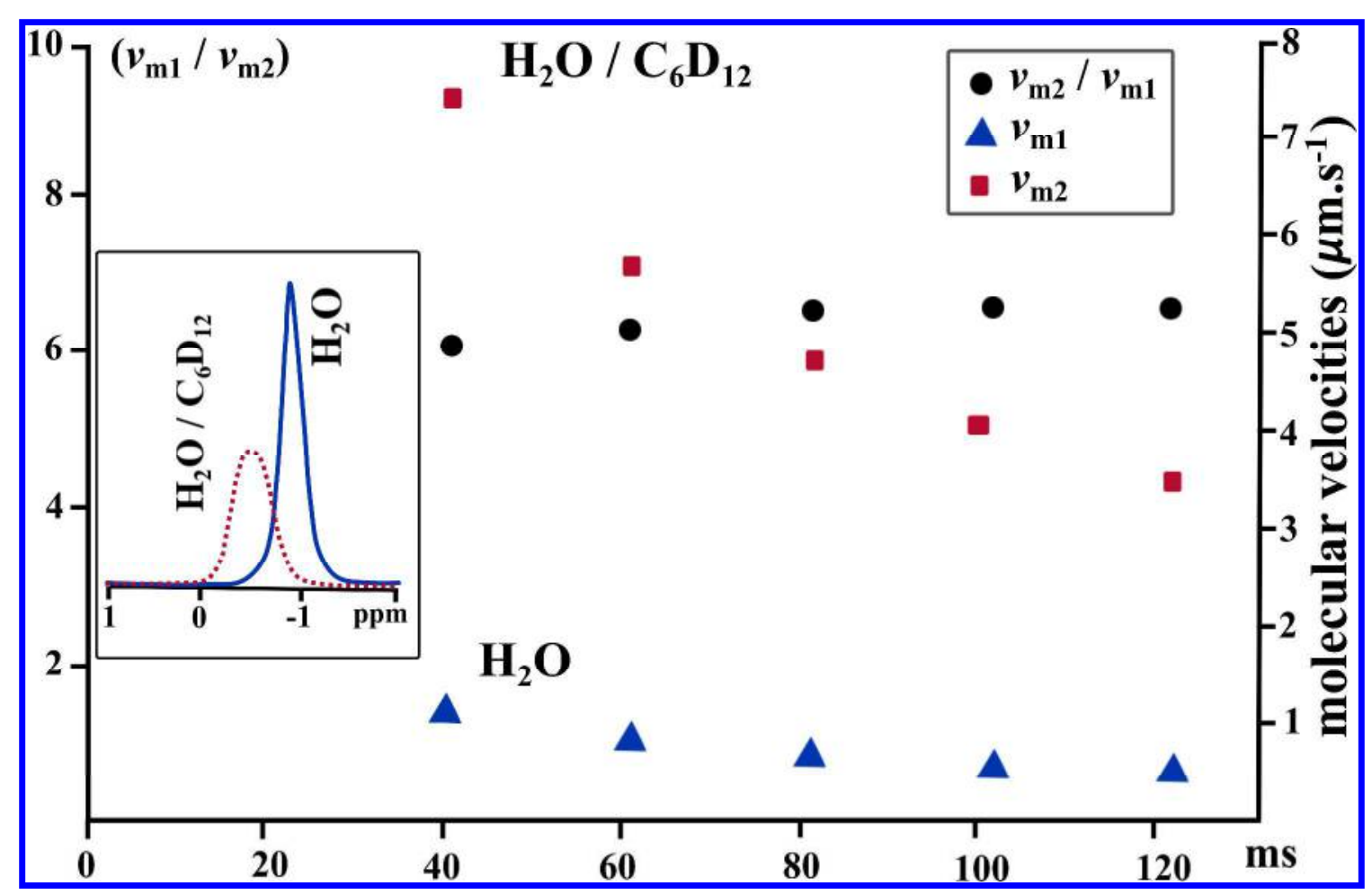

Figure 10. Measured $\mathrm{H}_{2} \mathrm{O}$ Molecular velocities $v_{\mathrm{m} 1}$ (only $\mathrm{H}_{2} \mathrm{O}$ loaded) and $v_{\mathrm{m} 2}$ (mixture $\mathrm{H}_{2} 0 / \mathrm{C}_{6} \mathrm{D}_{12}$ loaded) with respect to the observation time $\Delta$. Inset : MAS $9 \mathrm{kHz}$ spectra of THC515 loaded with $\mathrm{H}_{2} \mathrm{O}$ and a mixture of $\mathrm{H}_{2} \mathrm{O} / \mathrm{C}_{6} \mathrm{D}_{12}$ (dashed line).

\section{REFERENCES}

1 Sweatman, M. B.; Quirke, N. Characterization of Porous Materials by Gas Adsorption: Comparison of Nitrogen at $77 \mathrm{~K}$ and Carbon Dioxide at $298 \mathrm{~K}$ for Activated Carbon. Langmuir. 2001, 17 (16), 5011-5020. 


\footnotetext{
${ }^{2}$ Brunauer, S.; Emmet, P.; Teller E. Adsorption of gases in multimolecular layers. J. Am. Chem.Soc. 1938, 60 (2), 309-319.
}

${ }^{3}$ Ravikovich, P. I.; Neimark, A. V.; Llwellyn, F. R. P. Density functional theory model of adsorption on amorphous and microporous solids. In Characterization of Porous Solids VII Proceedings of the 7th International Symposium of the Characterization of Porous Solids (COPS VII), Aix-en-Provence, France, 26-28 May 2005. 2007, 160, 9-16.

${ }^{4}$ Neimark, A. V.; Ravikovich, P. I.; and Thommes, M. Quenched solid density functional theory end pore size analysis of micro-mesoporous carbons. Carbon. 2009, 47(7), 1617-1628.

${ }^{5}$ Boehm, H. Some aspects of the surface chemistry of carbon blacks and other carbons. Carbon. 1994, 32(5), 759-769.
${ }^{6}$ Toeckli, F.; Kraehenbuehl, F. The enthalpies of immersion of active carbons in relation to the Dubinin theory for the volume filling of micropores. Carbon. 1981, 19 (5), 353-356.
7 Toeckli, F.; Kraehenbuehl, F. The external surface of microporous carbons derived from adsorption and immersion studies. Carbon. 1984, 22 (3), 297-299.

\footnotetext{
${ }^{8}$ Gregg, S. J.; Sing, K. S. W. Adsorption surface and porosity. Academic Press, London. 1991.

9 Groszek, A. J.; Aharoni, C. Study of the Active Carbon-Water Interaction by Flow Adsorption Microcalorimetry. Langmuir. 1999, 15 (18), 5956-5960.
} 


\footnotetext{
${ }^{10}$ Berlier, K.; Frere, M. Adsorption of $\mathrm{CO}_{2}$ on active carbon: simultaneous determination of integral heat and isotherm of adsorption. L.Chem. Eng. Data. 1996, 41, 1144-1148.
}

${ }^{11}$ McNaughton, J. L.; Mortimer, C. T. Differential scanning calorimetry. Volume 10 of IRS Physical Chemistry Series 2. Butterworths, London, UK. 1975.

\begin{abstract}
12 Baudu, M.; Le Cloirec, P.; Martin, G. First approach of desorption energies of water and organic molecules onto active carbon by differential scanning calorimetry studies. Water Res.
\end{abstract} 1993, 27 (1), 69-76.

13 Sudibandriyo, M.; Pan, Z.; Fitzgerald, J. E.; Robinson, Jr, R. L.; Gasem, K. A. M. Adsorption of Methane, Nitrogen, Carbon Dioxide, and Their Binary Mixtures on Dry Activated Carbon at 318.2 K and Pressures up to 13.6 MPa. Langmuir. 2003, 19 (13), 5323-5331.

14 Le Cloirec, P. Les composés organiques volatils dans l'environnement. Tech \& Doc, Lavoisier, Paris, France 1998.
${ }^{15}$ Farmer, C. T.; Milne, P. J.; Riemer, D. J.; Zika, R. G. Continuous hourly analysis of C2-C10 non-methane hydrocarbon compounds in urban air by GC-FID. Environmental Science \& Technology. 1994, (28) 2, 238-245.

\footnotetext{
${ }^{16}$ Giraudet, S.; Le Cloirec, P.; Boulinguiez, B. Adsorption and Electrothermal Desorption of Volatile Organic Compounds and Siloxanes onto an Activated Carbon Fiber Cloth for Biogas Purification. Energy Fuels. 2014, (28) 6, 3924-3932.

${ }^{17}$ Bronnimann, C. E.; Maciel, G. E. ${ }^{13}$ C NMR Study of methanol in HY zeolite. J. Am. Chem. Soc. 1986, 108, 7154-7159.
} 
${ }^{18}$ Le Cloirec, P.; Martin, G.; Gallier J. ${ }^{1} \mathrm{H}$ NMR investigation on phenol saturated and unsaturated active carbon: quantification and exchange behavior of protons. Carbon, 1988, 26 (3), 275-282.

${ }^{19}$ Gun'ko, V. M.; Turov, V. V.; Kozynchenko, O. P.; Palijczuk, D.; Szmigielski, R.; Kerus, S. V.; Borysenko, M. V.; Pakhlov, E. M.; Gorbik, P. P. Characteristics of adsorption phase with water/organic mixtures at a surface of activated carbons possessing intraparticle and textural porosities. Anplied Surface Science. 2008, 254 (10), 3220-3231.

${ }^{20}$ Schmidt, R.; Walther Hansen, E.; Stocker, M.; Akporlaye, D.; Ellestad, O. H. Pore size determination of MCM-41 mesoporous materials of ${ }^{1} \mathrm{H}$ NMR Spectroscopy, $\mathrm{N}_{2}$ adsorption, and HREM. A preliminary study. J. Am. Chem. Soc. 1995, 117, 4049-4056.

${ }^{21}$ Stallmach, F.; Graser, A.; Karger, J.; Krause, C.; Jeschke, M.; Oberhagemann, U.; Spange, S. Pulsed field gradient NMR studies of diffusion in MCM-41 mesoporous solids. Microporous and Mesoporous Materials. 2001, 44-45, 745-753.

\footnotetext{
${ }^{22}$ Dvoyaskin, M.; Khoklov, A.; Naumov, S.; Valiulllin, R. Pulsed field gradient NMR study of surface in mesoporous adsorbents. Microporous and Mesoporous Materials. 2009. 125, 58-62.

23 Valiulllin, R.; Kortunov, P.; Karer, V.; Timoshenko, V. Concentration-dependent selfdiffusion of liquids in nanopores: A nuclear magnetic resonance study. Magnetic Resonance Imaging. 2005. (23) 2, 209-214.
} 


\begin{abstract}
24 Anderson, R. J.; McNicholas, T. P.; Kleinhammes, A.; Wang, A.; Liu, J.; Wu, Y. NMR Methods for Characterizing the Pore Structures and Hydrogen Storage Properties of Microporous Carbons. J.Am.Chem.Soc. 2010. 132 (25), 8618-8626.

${ }^{25}$ Forse, A. C.; Griffin, J. M.; Wang, H.; Trease, N. M.; Presser, V.; Gogotsi, Y.; Simon, P.;
\end{abstract} Grey, C. P. Nuclear magnetic resonance study of ion adsorption on microporous carbide-derived carbon. Phvs. Chem. Chem. Phvs. 2013. 15 (20), 7722-7730.
${ }^{26}$ Deschamps, M.; Gilbert, E.; Azais, P.; Raymundo-Piñero, E.; Ammar, M. R.; Simon, P.; Massiot, D.; Béguin, F. Exploring electrolyte organization in supercapacitor electrodes with solid-state NMR. Nature Materials. 2013, 351-358.
${ }^{27}$ Mueller, R.; Kanungo, R.; Kiyono-Shimobe, M.; Koros, W. J.; Vasenkov, S. Diffusion of Methane and Carbon Dioxide in Carbon Molecular Sieve Membranes by Multinuclear Pulsed Field Gradient NMR. Langmuir. 2012, 28 (27), 10296-10303.
28 Shaw, J. A.; Harris, R. K.; Norman, P. R. Magic-Angle Spinning NMR Study of the Competitive Adsorption of an Organophosphate and an Organophosphonate on Activated Carbon. Langmuir. 1998, 14 (23), 6716-6721
${ }^{29}$ Harris, R. K.; Thompson, T. V.; Norman, P. R.; Pottage, C. Phosphorus-31 NMR studies of adsorption onto activated carbon. Carbon. 1999, 37 (9), 1425-1430.




\begin{abstract}
30 Harris, R. K.; Thompson, T. V.; Forshaw, P.; Foley, N.; Thomas, K. M.; Norman, P. R.; Pottage, C. A magic-angle spinning NMR study into the adsorption of deuterated water by activated carbon. Carbon. 1996, 34 (10), 1275-1279.
\end{abstract}
${ }^{31}$ Romanova, E.E.; Grinberg, F.; Pampel, A.; Kärger Jörg.; Freude, D. Diffusion Studies in confined liquid crystal by MAS PFG NMR. Journal of Magnetic Resonance. 2009. 196, 110- 114.

${ }^{32}$ Xu, Y.; Watermann, T.; Limbach, H-H.; Gutmann, T.; Sebatiani, D.; Buntkowsky, G. Water and small organic molecules as probes for geometric confinement in well-ordered mesoporous carbon materials. Phvs. Chem. Chem. Phvs. 2014. 16, 9327.

${ }^{33}$ Levitt, M. Spin Dynamics. Basic of Nuclear Magnetic Resonance. 2008. Wiley.

${ }^{34}$ Duer, M. J. Solid-state NMR spectroscopy: principles and applications. Duer. 2008. WileyBlackwell Science.
${ }^{35}$ Callaghan, P. T. Principles of Nuclear Magnetic Resonance Microscopy. Oxford Science Publication. 1991. Oxford University Press. New York.
${ }^{36}$ Callaghan, P. T.; Coy, A.; Halpin, T. P. J.; MacGowan, D.; Packer, K. J. Diffusion in porous systems and the influence of pore morphology in pulsed field gradient spin-echo nuclear magnetic resonance studies. L.Chem. Phvs. 1992, 97 (1), 651-662.
${ }^{37}$ Ruthven, D. M. in Karge, H. G.; Weitkamp, J. Adsorption and Diffusion. Springer. 2008. Berlin, Heidelberg. pp. 1-43.




\begin{abstract}
${ }^{38}$ Giraudet S.; Boulinguiez B.; Le Cloirec P.; Adsorption and Electrothermal Desorption of Volatile Organic Compounds and Siloxanes onto an Activated Carbon Fiber Cloth for Biogas Purification. Energv Fuels. 2014, 28 (6), pp 3924-3932.
\end{abstract}
${ }^{39}$ Boulinguiez, B.; Le Cloirec, P. Chemical transformations of sulfur compounds adsorbed onto activated carbon materials during thermal desorption. Carbon. 2010. 48 (5), 1558 -1569.
${ }^{40}$ Hahn, E. L. Spin Echo. Phvs. Rev. 1950, 80 (4), 1-6.

${ }^{41}$ Ganguli, N.; Krishnan, K. S. The Magnetic and Other Properties of the Free Electrons in Graphite. Proc.R.Soc.London. 1941, 177 (969), 168-182.
${ }^{42}$ Heremans, J.; Olk, C. H.; Morelli, D. T. Magnetic Susceptibility of Carbon Structures. Phys. Rev.B. 1994, 49 (21), 15122-15125.

${ }^{43}$ Heremans, J.; Olk, C. H.; Morelli, T. Magnetic susceptibility of carbon structures. Phys. Rev. 1994, B 49, 15122.
${ }^{44}$ Pople, J. A. Proton Magnetic Resonance of Hydrocarbons. L.Chem. Phvs. 1956, 24, 1111.
${ }^{45}$ Carrington, A.; McLachlan, A. D. Introduction to Magnetic Resonance with Applications to Chemistry and Chemical Physics. Harper International Edition. 1967. Harper \& Row. New York. pp. 58-61.
${ }^{46}$ Tabony, J.; White, J. W. Nuclear magnetic resonance studies of the melting and orientation of benzene adsorbed upon graphite. Surface Science Letters. 1980, 95 (2-3), 282-288.




\footnotetext{
${ }^{47}$ Vernovt, A.; Steele, W. A. Computer Simulation of Benzene Adsorbed on Graphite. 1.85K. Langmuir. 1991, 7 (12), 3110-3117.

${ }^{48}$ Chakarova-Käck, S. D.; Schröder, E.; Lundqvist, B. I.; Langreth, D. C. Application of van der Waals Density Functional to an Extended System: Adsorption of Benzene and Naphthalene on Graphite. Phys. Rev. Lett. 2006, 96.146107.

49 Zeigermann, P.; Naumov, S.; Mascotto, S.; Kärger, J.; Smarsly, B.M.; Valiulin, R. Diffusion in Hierarchical Mesoporous Materials: Applicability and Generalization of the Fast-Exchange Diffusion Model. Langmuir. 2012, 28 (7), 3621-3632.
}

50 Ruthven, D. M. Principles of Adsorption and Adsorption Processes. 1984. WileyInterscience, New-York, USA.

${ }^{51}$ Do, D. D. Dynamics of a semi-batch adsorber with constant molecular supply rate: a method for studying adsorption rate of pure gases. Chemical Engineering Science. 1995, 50 (3), 549-553.

${ }^{52}$ Prasetyo, I.; Do, H. D.; Do, D. D. Surface diffusion of strong adsorbing vapours on porous carbon. Chemical Engineering Science. 1995, 57, 387-394.

${ }^{53}$ Chiang, H. L.; Chiang, P. C.; Chiang, Y. C.; Chang, E. E. Diffusivity of Microporous Carbon for Benzene and Methyl-Ethyl Ketone adsorption. Chemosphere. 1999, 38(12), 27332746.

\footnotetext{
${ }^{54}$ Furtado, F.; Galvosas, P.; Gonçalves, M.; Kopinke, F. D.; Naumov, S.; Rodríguez-Reinoso, F.; Roland, U.; Valiullin, R.; Kärger, J. Guest diffusion in interpenetrating networks of microand mesopores. J.Am.Chem.Soc. 2011, 133 (8), 2437-2443.
} 


\begin{abstract}
55 Adem, Z.; Guenneau, F.; Springuel-Huet, M.A.; Gédéon, A.; Iapichella, J.; Cacciaguera, T.;
Galarneau, A. Diffusion Properties of Hexane in Pseudomorphic MCM-41 Mesoporous Silica Explored by Pulsed Field Gradient NMR. L.Phvs. Chem.C, 2012, 116 (25), pp 13749-13759
\end{abstract}

${ }^{56}$ Alam, T.M.; Osborn Popp, T.M. In-pore Exchnage and Diffusion of Carbontate Solvent Mixtures in Nanoporous Carbon. Chemical Phvsics Letters, 2016, 658, 51-57.

57 Forse, A.C.; Merlet, C.; Griffin, J.M.; Grey, C.P. New Perspectives on the Charging Mechanisms of Supercapacitors. J.Am. Chem. Soc., 2016, 138, 5731-5744.

${ }^{58}$ Griffin, J.M.; Forse A.C.; Grey C.P.; Solid-state NMR Studies of Supercapacitors. Solid State Nuclear Magnetic Resonance 74-75, 2016, 16-35.

${ }^{59}$ Forse A.C.; Griffin, J.M.; Merlet, C.; Bayley, P.M.; Wang, H.; Simon, P.; Grey, C.P. NMR Study of ion Dynamics and Charge Storage in ionic Liquid Supercapacitors. J. Am. Chem. Soc., 2015, 137, 7231-7242.

\title{
$\underline{\text { TOC graphic }}$
}




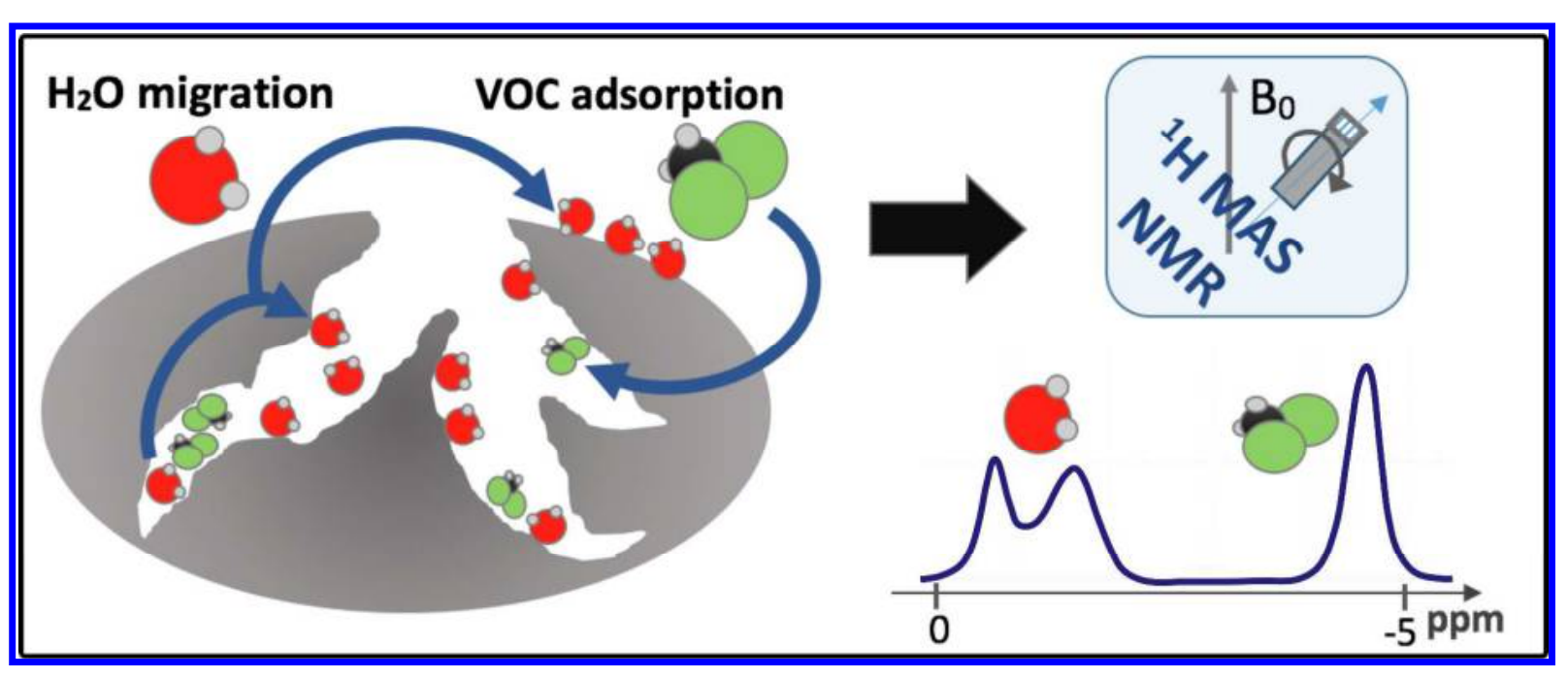

1
2
3
4
5
6
7
8
9
10
11
12
13
14
15
16
17
18
19
20
21
22
23
24
25
26
27
28
29
30
31
32
33
34
35
36
37
38
39
40
41
42
43
44
45
46
47
48
49
50
51
52
53
54
55
56
57
58
59
60

30

32 